EDUR • Educação em Revista. 2020; 36:e222213

DOI: http://dx.doi.org/10.1590/0102-4698222213

() (1) https://creativecommons.org/licenses/by/4.0/

ARTIGO

\title{
EDUCAR CORPOS, COSTUMES E SENSIBILIDADES: PRÁTICAS CULTURAIS ESTADUNIDENSES E INTERPRETAÇÕES SOBRE O BRASIL EM CIRCULAÇÃO PELA ASSOCIAÇÃO CRISTÃ DE MOÇOS
}

\author{
GIOVANNA CAMILA DA SILVA ${ }^{1}$ \\ ORCID: https://orcid.org/0000-0002-5705-0573
}

\begin{abstract}
RESUMO: A inauguração da Associação Cristã de Moços no Brasil e a expansão do seu projeto formativo contaram com um importante elemento atrativo: o protestantismo. Em finais do século XIX já circulavam no país ideias, proposições e práticas afinadas com a estrutura religiosa da Associação. Com a chegada de instituições e sujeitos estadunidenses no Brasil, aportavam no país formas de viver sintonizadas com padrões estadunidenses de operar no mundo. De forma sutil ou de modo explícito, é possível identificar elementos mobilizados também pela ACM para aproximação dos brasileiros com práticas culturais, com valores, com o modo de vida "americano". Nas representações produzidas sobre o Brasil, os acemistas articularam um mecanismo que ora indicava as condições desfavoráveis do país, ora as tomava como mote para a ressonância das iniciativas da Associação. Indicar limitações, mas também apresentar alternativas para novos costumes, novas práticas, novas sensibilidades, essa parecia a dinâmica acemista.
\end{abstract}

Palavras-chave: História da Educação, Associação Cristã de Moços, educação do corpo, costumes, sensibilidades.

\section{EDUCATE BODIES, CUSTOMS AND SENSIBILITIES: NORTH AMERICAN CULTURAL PRACTICES AND INTERPRETATIONS ABOUT BRAZIL PUT INTO CIRCULATION BY THE YOUNG MEN'S CHRISTIAN ASSOCIATION}

\begin{abstract}
The inauguration of the Young Men's Christian Association in Brazil and the expansion of its formative project had an important attractive element: Protestantism. By the end of the nineteenth century, ideas, propositions and practices aligned with the religious structure of the Association were already circulating in the country. With the arrival of North American people and institutions in Brazil, living habits like those from the United States were promoted. It is possible to identify subtle and explicit elements employed by the YMCA to familiarize Brazilians to cultural practices, values, and the American way of life. In the representations produced about Brazil, the YMCA missionaries indicated the unfavorable conditions of the country, to introduce them as grounds for the resonance of the association's initiatives. The YMCA dynamics were to indicate limitations, but also to present alternative new customs, new practices, new sensibilities.
\end{abstract}

Keywords: History of education, Young Men's Christian Association, body education, customs, sensibilities.

\footnotetext{
${ }^{1}$ Universidade Federal de Minas Gerais (UFMG). Belo Horizonte, MG, Brasil. <giovannaufmg@yahoo.com.br> Educação em Revista|Belo Horizonte|v.36|e222213|2020
} 


\section{EDUCAR CUERPOS, COSTUMBRES Y SENSIBILIDADES: PRÁCTICAS CULTURALES ESTADOUNIDENSES E INTERPRETACIONES DE BRASIL PUESTOS EN CIRCULACIÓN POR LA ASOCIACIÓN CRISTIANA DE JÓVENES}

RESÚMEN: La inauguración de la Asociación Cristiana de Jóvenes en Brasil y la expansión de su proyecto de formación tuvieron un elemento atractivo importante: el protestantismo. A finales del siglo XIX, ideas, proposiciones y prácticas en sintonía con la estructura religiosa de la Asociación ya circulaban en el país. La llegada de las personas y instituciones estadounidenses en Brasil, trajeron al país formas de vivir en sintonía con los estándares estadounidenses. De manera sutil o explícita, es posible identificar elementos movilizados también por la ACJ para acercar a los brasileños a las prácticas culturales, con valores, con el estilo de vida "americano". En las representaciones producidas sobre Brasil, los acemistas articularon un mecanismo que a veces indicaba las condiciones desfavorables del país y otras las tomaban como la posibilidad para la resonancia de las iniciativas de la Asociación. Indique limitaciones, pero también presente alternativas para nuevas costumbres, nuevas prácticas, nuevas sensibilidades, esta parecía ser la dinámica de la ACJ.

Palabras clave: Historia de la educación, Asociación Cristiana de Jóvenes, educación del cuerpo, costumbres, sensibilidades. 


\section{INTRODUÇÃO}

A Young Men's Christian Association (YMCA) teve marcada presença nos Estados Unidos e expandiu-se por diferentes lugares ao redor do mundo ${ }^{2}$. No ano de inauguração da primeira sede da Associação Cristã de Moços (ACM) no Brasil, 1893, era também publicado o livro intitulado $A$ ilusão americana, de autoria de Eduardo Prado ${ }^{3}$. Como uma espécie de alerta, o autor posicionava-se, no momento inicial da República no Brasil, a respeito de equívocos na transplantação para o país de padrões da cultura estadunidense. Tomando para análise a obra do autor, Oliveira (2004) discorre que, para Prado, entre o Brasil e os Estados Unidos "existe um verdadeiro abismo cultural, com separação de raça, de religião, de índole, de língua, de história e de tradições. Portanto, nada deveria levá-los a possuir as mesmas instituições e a mesma forma de governo" (p. 138). Mesmo diante do alerta, instituições estadunidenses foram se acomodando no país. Nessa trama, é possível sugerir que, ao mesmo tempo em que a inserção da Associação Cristã de Moços no Brasil pode ser compreendida a partir de um contexto de americanização do fim do século XIX, pode ser também entendida como dispositivo que produziu condições para a inserção de outras entidades daquele país estrangeiro, nas décadas iniciais do século XX.

Partindo da ambiência de inserção e expansão da ACM no Brasil é que pretendo desenvolver o argumento, ancorado nas contribuições de Meurer e Taborda de Oliveira (2016), de que o corpo, os costumes e as sensibilidades compuseram um arranjo formativo mobilizado pela e a partir da Associação Cristã de Moços. No caso deste texto, os muros da instituição escolar são extrapolados e outros espaços da cidade são também mobilizados. Fundamentalmente, os elementos trazidos para a narrativa dão visibilidade para um conjunto de componentes do que se constituía o repertório educacional de inspiração protestante; do que se forjou sobre a cultura estadunidense e a brasileira; e do que se pretendia para esse encontro cultural. A investigação sobre esses elementos permitiu colocar em evidência o lugar e os sentidos dos usos do corpo, e os significados relativos aos saberes e às práticas que agiriam sobre os modos de educar costumes e sensibilidades.

Se as agências estadunidenses se instalavam no Brasil, junto com elas, chegavam os sujeitos estrangeiros e seus códigos culturais. O "andar à americana", o uso do cigarro, o cinema, a incorporação de palavras de origem estrangeira... (SEVCENKO, 1998). Destaque-se, também, que algumas dessas entidades promoviam o trânsito de brasileiros aos Estados Unidos, os quais ao voltarem, traziam consigo elementos da cultura do outro país ${ }^{4}$.

Do imbricado de referências culturais, ganha destaque a inserção do protestantismo no Brasil, já que a dimensão religiosa constituiu elemento atrativo que possibilitou à ACM expandir seu projeto de formação para um país que já apresentava alguma circulação de ideias, proposições e práticas afinadas com seu empreendimento. Como esse processo não se deu sem conflitos, a relação de enfrentamento com os católicos dá a ver a disputa por legitimidade de sentidos para a religião, a educação e os costumes.

Pretenderam os catholicos desta cidade impedir o bom exito da subscripção da Associação Christã de Moços. Pregaram contra ella no pulpito, aconselharam pelos jornaes e por meio de

\footnotetext{
${ }^{2}$ Originada na Inglaterra em 1844, a YMCA, no seu movimento de expansão, iniciou a ampliação de sedes na Europa em 1851, mesmo ano em que se instalou no continente americano. Um arranjo de ações indica que os Estados Unidos passaram a assumir centralidade na organização de iniciativas da Associação. Podem ser citadas o desenvolvimento de sedes instaladas na América do Norte - no final do século XIX, eram 1415 -, a criação da Comissão Internacional das YMCA’s em 1879, com sede em Nova Iorque, e a circulação de missionários acemistas de origem estadunidense. Ao mesmo tempo em que a Associação teve acolhida naquele país estrangeiro, acabou sendo por ele também produzida. (SILVA, 2017).

3 "Recolhido logo após sua publicação, em 1893, o livro teve uma segunda edição em Paris, em 1896, e foi sucessivamente reeditado no Brasil em 1902, 1933, 1957 e 1980” (OLIVEIRA, 2004, p. 137).

${ }^{4}$ Merece menção a dinâmica da inserção de ideias e práticas de protestantes educadores no Brasil que envolveu um duplo movimento: o envio de missionários ao nosso país e a ida de professorado brasileiro aos Estados Unidos para formação nos seus preceitos de ensino. Essa estrutura sistematizada de chegada de sujeitos estadunidenses para iniciar as atividades de um projeto de formação, e de preparação no exterior dos brasileiros de modo a dar continuidade à qualidade do trabalho estrangeiro parece comum às agências estadunidenses. A Associação Cristã de Moços e a Fundação Rockefeller procedem de forma semelhante.
} 
circulares que the não dessem migalha. Por que? Porque, disseram, a religião que ella professa não é a catholica, apostolica, romana. (...) Para esses sectarios intolerantes, a unica religião verdadeira é a catholica, apostolica, romana; fóra della não ha salvação, clamaram elles ao povo, para induzil-o pelo terror do inferno - um dos seus processos de dominio - a não contribuir para uma obra de educação e de moralidade. (...)

O protestantismo é o primeiro estádio da liberdade do pensamento em materia religiosa; elle é a religião sobre todas favoravel á instrucção, á liberdade religiosa e politica; ao progresso, ao "selfgovernment"; os Estados protestantes são nitidamente superiores aos catholicos, na politica, na ordem, no commercio, na industria, na cultura intellectual; o seu clero é superior intellectual e moralmente 5 .

Escritos por Placido Barbosa, esse fragmento de texto foi publicado sob o título de A.C.M. em um diário de notícias do Rio de Janeiro que, embora intitulado $O$ imparcial, objetivamente posicionouse a favor da ACM e sua orientação protestante. Os destaques produzidos pelo autor colocavam em circulação elementos centrais do modo de operar com o mundo forjados pelo protestantismo: a liberdade, a atividade individual e a expectativa de formar uma sociedade instruída e em constante desenvolvimento, que contrastavam com a doutrinação pela religião católica.

\section{REPERTÓRIOS EDUCACIONAL E CULTURAL: MISSÕES PROTESTANTES E OS ESTADOS UNIDOS COMO CAMINHO PARA FORMAÇÃO}

O movimento de propagação da fé reformada pelos missionários que vieram dos Estados Unidos para o Brasil na segunda metade do século XIX, constituiu-se, para Mendonça (1984), como um projeto civilizador cuja centralidade era fazer ressoar pelos diferentes cantos do mundo a ideia da conversão baseada na experiência pessoal com Deus. Investidos de superioridade e orientados pela doutrina do Destino Manifesto, os missionários consideravam-se o povo eleito de Deus para propagar um novo ethos, uma nova visão de mundo estreitamente ligada aos valores estadunidenses em busca de uma sociedade "religiosa, livre, letrada, industriosa, honesta e obediente às leis" (MENDONÇA, 1984, p. 55). Era a crença na constituição de uma civilização cristã modelar, na qual Deus agiria por intermédio dos povos escolhidos, especialmente aqueles de língua inglesa. Como elemento dessa nova organização da vida, o tripé religião-moralidade-educação cumpria uma função normativa que regulava a vida social em muitos aspectos. Articulando a expectativa de expansão de uma civilização cristã às ideias do destino manifesto, Mesquida (1994) afirma que este transformou-se em convicção generalizada nos Estados Unidos durante o século XIX, configurando uma dupla implicação: reafirmar a superioridade dos brancos sobre os negros recém-libertos, mas dominados por outros mecanismos, e animar o movimento expansionista daquele país.

Chamon (2005) afirma que a educação e o trabalho eram os meios pelos quais o cristão reformado deveria buscar se aperfeiçoar, desenvolvendo os dons dados a ele por Deus e não se deixando atrair ou envolver pelas tentações presentes no mundo. Era essa busca pela perfeição e o êxito que demonstraria a superioridade da fé reformada. A preocupação com a educação foi demonstrada por diferentes dispositivos de formação, como afirma Mendonça (1984). As escolas dominicais assumiram a função de ensino religioso. Tais instituições desempenharam importante papel no desenvolvimento e consolidação das igrejas protestantes. Uma outra versão da preocupação com a educação pode ser percebida no surgimento de associações que se constituíram também como agências missionárias, como a YMCA que, na amplitude de ações empreendidas, especialmente destinadas aos jovens do sexo masculino, destacando-se as de caráter social, educacional, e físico, não perdia de vista o desenvolvimento de virtudes e conhecimentos cristãos. Também importante como atividade missionária educativa, a distribuição de bíblias era baseada na crença de que sua leitura formaria mentes e sentimentos cristãos, condição básica para a conversão dos sujeitos.

Tarefa missionária, a educação escolar foi um dos meios de atuação de agentes encarregados de divulgar a fé reformada no Brasil. O investimento na educação do povo estava sintonizado com ideais

\footnotetext{
5 O Imparcial, 28 de outubro de 1917, p. 4 (grifos do autor).

Educação em Revista|Belo Horizonte|v.36|e222213|2020
} 
do movimento republicano, que apostava que a democracia e a liberdade realizar-se-iam por intermédio da instrução popular. Como atribuições da escola figuravam um trabalho persistente sobre a opinião pública, a formação de potenciais intelectuais republicanos e a preparação dos sujeitos para o exercício da democracia. Mesquida (1994) comenta que esse modo de pensar a educação estava informado pelo modelo cultural e político dos Estados Unidos. Educação nova, baseada em experiência prática, fonte de liberdade, trabalho, progresso. Abalizados por uma conexão com seus princípios e suas ações, os republicanos brasileiros apoiaram a abertura de instituições de ensino empreendidas pelo movimento missionário estadunidense. Uma pedagogia com características capazes de aperfeiçoar o povo rumo ao progresso e uma versão religiosa dos ideais liberais e democráticos são elementos que vincularam republicanos à educação missionária.

Junto à necessidade de combater o analfabetismo, o estabelecimento de escolas protestantes seria uma maneira indireta de demonstrar e difundir os valores de sua religião. A compreensão de que o conhecimento retirava a ignorância do homem e o fazia um sujeito responsável por suas ações, capaz de se aperfeiçoar, expandir suas forças individuais e, assim, contribuir para o progresso moral e material da sociedade e a consequente promoção do Reino dos Céus marcou a educação presbiteriana no Brasil, conforme os estudos de Chamon (2005). "Assim, valores como liberdade, democracia, progresso e responsabilidade individual eram veiculados na prática educativa desses missionários e de sujeitos que gravitavam ao redor deles" (CHAMON, 2005, p. 88) e configuravam projetos para formação de uma civilização cristã conectados com princípios do liberalismo estadunidense.

A inserção no Brasil de estabelecimentos escolares de origem protestante ${ }^{6}$ permitiu que fossem experimentados aqui alguns dos processos pedagógicos vivenciados nos Estados Unidos, especialmente a coeducação dos sexos, o ensino a partir do método intuitivo, e a preferência pela mulher na instrução primária. Tais colégios contavam com um professorado qualificado, com muitos docentes formados naquele país estrangeiro. Sua estrutura material era comumente superior às condições brasileiras e uma ideia de inovação permeava sua organização pedagógica e seus métodos de ensino. "A grande novidade dessas escolas, insistentemente apontada pelos autores que se dedicam ao tema, é que essas modernidades pedagógicas vinham imbricadas com os princípios norteadores da religião protestante: liberdade e individualismo" (CHAMON, 2005, p. 92). A renovação de ideias e práticas pedagógicas era, por extensão, uma reforma do povo brasileiro.

A liberdade religiosa, política, de crítica, de discussão foi destacada por Ramalho (1976) como uma característica da prática educativa dos colégios protestantes seguindo a compreensão de que a constituição da "humanidade de um homem é ser livre da dependência da vontade dos outros homens" (p. 147). Nesse sentido, a centralidade no indivíduo conduz a um entendimento de que os sujeitos escolhem o curso de suas vidas. "Os destaques na escola, e principalmente na vida, são obtidos por aqueles que mais se 'esforçam', que têm 'força de vontade' e possuem um bom caráter”' (p. 147, grifos do autor). Responsabilidade pessoal era a tônica, inclusive quando a referência eram os códigos de conduta moral. A partir de uma perspectiva que considerava a avaliação da educação por aquilo que os sujeitos são e fazem, o autor comenta "o orgulho com que os colégios apontam como comprovação da eficiência do seu ensino, o sucesso individual alcançado pelos seus alunos, que têm êxito na vida, medido através de bons empregos e altos postos de poder" (RAMALHO, 1976, p. 149, grifos do autor). O valor do esforço individual vai encontrar elementos de coesão na ideia de vocaşão, tão presente na forma protestante de operar com o mundo. Ramalho (1976) evidencia que nos colégios protestantes "o trabalho é visto como uma vocação e constitui antes de mais nada a própria finalidade da vida, sendo que o êxito - sinal de

\footnotetext{
6 “De origem presbiteriana: 'Colégio Internacional', instalado em Capinas/SP em 1869, transferido para Lavras/MG em 1893 e posteriormente chamado de 'Instituto Gammon'; 'Escola Americana' (hoje Mackenzie), instalada em São Paulo, 1870; 'Colégio Morton', instalado em São Paulo, em 1880; 'Escola Americana' de Curitiba em 1892. De origem metodista: 'Colégio Piracicabano’ em 1881; 'Escola do Alto', no Rio de Janeiro em 1882 e transferida para Juiz de Fora em 1891 sob o nome de 'Colégio Mineiro'; 'Colégio Granbery', de Juiz de Fora em 1889; 'Colégio Americano Fluminense', 1892; 'Colégio de Petrópolis', 1895; 'Colégio Metodista', em Ribeirão Preto, 1899; 'Colégio Isabela Hendrix', de Belo Horizonte, em 1904” (CHAMON, 2005, p. 90). "Entre os batistas as primeiras iniciativas são de 1888, quando foi inaugurada uma escola no Rio de Janeiro. Depois vieram outras em Salvador (1894), Campos (1896), Belo Horizonte (1898), Recife e São Paulo (1902), Vitória (1908) (...)" (CALVANI, 2009, p. 56).
} 
aprovação da sociedade e de Deus - só pode ser obtido através dele, não resultado de privilégios e discriminações" (p. 155, grifo do autor). Segundo o autor, não se tratava de preparar o aluno para exercer um ofício, mas de configurar o trabalho como um valor social que mobilizasse os sujeitos para a independência, a atividade individual, o desenvolvimento intelectual, físico e moral, a perseverança, enfim, para a incorporação de uma multiplicidade de hábitos e atitudes com utilidade na vida prática.

Desse modo, trabalho, esforço, caráter seriam exercidos e incorporados por intermédio de atividades "úteis", a educação deveria estar voltada para a vida. Essa é uma ênfase pedagógica comum às instituições educacionais protestantes. "A busca da correlação das matérias e a verificação de sua utilidade para a vida são procedimentos habituais", enfatiza Ramalho (1976, p. 152). O autor assinala a presença constante da Educação Física nos colégios de orientação protestante e ressalta que a expectativa de preparação dos sujeitos para a vida prática levou a um interesse pela matéria. A contratação de professores especializados, a introdução de novos esportes, o incentivo a competições e a organização de clubes são destacados como características que permeavam a presença da Educação Física naquelas instituições educativas.

Figura 1: Vista parcial dos campos esportivos do Granbery

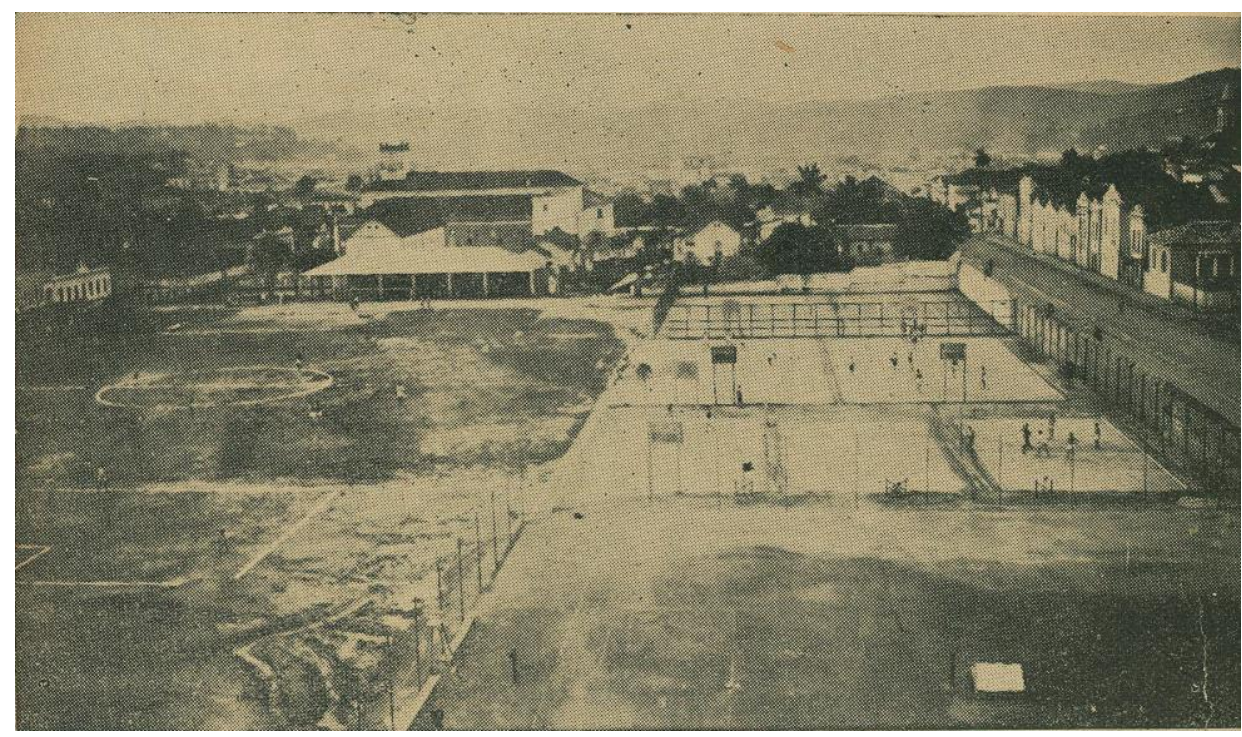

Fonte: Revista Educação Physica, n. 6, set. 1936, p. 72.

O desenvolvimento de um corpo são fortaleceria o espírito para o próprio proveito e para uma utilidade social. Assim compreendido, o físico apresenta-se como importante elemento na educação protestante e a ACM aparece atuante em alguns estabelecimentos de ensino, onde fez ressoar elementos presentes em sua modelagem para uma Educação Física nas escolas. Os colégios e a Associação partilhavam o entendimento sobre a necessidade de desenvolvimento integral dos sujeitos. Para os estabelecimentos escolares de orientação protestante, o ensino eficiente precisaria atingir o indivíduo em sua totalidade, nas dimensões do espírito, da mente, do físico, ainda que numa relação desigual. "Há uma hierarquização nesses aspectos - a educação física é um meio para facilitar a cultura intelectual (necessária para um mundo racional), mas subordinada ao fim maior que é a formação do caráter" (RAMALHO, 1976, p. 156). Para a ACM, a integralidade estava expressa no símbolo que a identificava:

O triangulo equilatero, equilibrado sobre um dos vertices, é o emblema universal das A.C.M. Elle symboliza o equilibrio da personalidade pelo cultivo harmonico dos seus tres elementos essenciaes: alma, corpo, mente. Não é alvo da A.C.M. fazer athletas, nem intellectuaes, nem mysticos, mas homem, na mais completa e mais nobre accepção desta palavra. A' trilogia do 
emblema correspondem os tres valores com que o moço deve contar na vida para o serviço altruista da communidade: saude, intelligencia, caracter ${ }^{7}$.

A parceria estabelecida entre as agências missionárias era estampada nas páginas do periódico oficial da ACM, intitulado "Mocidade". então instrutor de Educação Física no Instituto Evangélico, produziu um histórico sobre a presença da ginástica e dos jogos na cidade mineira, e ressaltou a atuação da ACM no referido estabelecimento de ensino: "Em meiados de 1916, o Collegio foi visitado pelo sr. H. J. Sims que planejou e organizou o primeiro trabalho de educação physica nos moldes da ACM.; ficando então entregue aos cuidados do nosso collega e amigo Eloy Renato de Andrade" . A presença de sujeitos que tiveram algum tipo de instrução na Associação para trabalhar com a Educação Física nas escolas parecia comportar uma dimensão estratégica de troca ${ }^{10}$. Por um lado, a Associação fazia ressoar suas ideias e práticas de formação física para além dos muros de sua sede, por outro, os colégios protestantes confiavam o ensino a instrutores informados por referências e valores comuns à sua estrutura educativa-religiosa. Essa parecia a tônica de um encontro entre professores e o diretor físico da ACM: "A convite do Director do Primeiro Instituto dos Professores dos Collegios Protestantes do Brasil, o Director de Educação Physica do Rio, sr. H. J. Sims, realizou uma conferencia sobre a educação physica nos collegios" ${ }^{11}$. Menos que acaso, as fontes indicam intencionalidade nesse mecanismo de lastro das ações acemistas. Era mais um empreendimento da instituição.

\section{A educação physica nos collegios \\ Em dias do mez passado, realizou o Collegio Baptista uma excursão á Juiz de Fóra, onde disputou com o Gymnasio Granbery desta localidade uma serie de jogos de Volley, Basket e Football. \\ E' mais um producto do serviço da ACM do Rio, pois della saiu o actual instructor do Collegio Baptista, o Sr. M. R. Santos ${ }^{12}$.}

O próprio M.R. Santos, citado na publicação, destacava o protagonismo de diretores técnicos formados pela ACM na condução dos esportes em instituições protestantes de ensino. Em texto intitulado Campeonatos Collegiaes, o professor de Educação Física anunciava, como um relato histórico, a prática do basquete no Colégio Gammon em Lavras, sob a direção de Renato Eloy de Andrade, e seu próprio protagonismo no Colégio Batista, onde passou a dirigir o departamento de Educação Física em 1920. Nas palavras do autor, encontramos indícios que reforçam a ênfase dada aos esportes pelos colégios protestantes, como afirmado por Ramalho (1976). Referia-se M. R. Santos a uma parceria estabelecida entre o Colégio Batista, o Colégio Gammon e o Instituto Granbery que organizaram uma liga colegial interestadual. O campeonato contava com competições de diferentes esportes e era realizado a cada ano na sede de um dos colégios ${ }^{13}$.

Destaque-se uma característica que credenciava os colégios protestantes “americanos" no Brasil: a presença de professores especializados para o ensino, condição para a eficiência e seriedade do trabalho pedagógico. O Colégio Batista propagandeava essa preocupação em seu anúncio: "corpo docente criteriosamente escolhido e de reconhecida competência" e, talvez pelo veículo escolhido para o reclame - um periódico especializado em Educação Física - distinguia tal campo: "as aulas de Educação Fisica são ministradas por um instrutor tecnico competente, de acordo com as necessidades de cada

\footnotetext{
${ }^{7}$ Revista Educação Physica, n. 2, dez. 1932, p. 13.

${ }^{8}$ O periódico oficial da Associação Cristã de Moços inicialmente foi intitulado "ACM", em seguida foi denominado "Amigo da Mocidade", depois foi chamado de "Canaan", e em 1913 passou a ser nomeado como "Mocidade".

${ }^{9}$ Mocidade, abril de 1923 , n. 350, p. 10. É provável que haja um engano na ordem do nome. Pela sua trajetória na ACM, tudo indica tratar-se de Renato Eloy de Andrade.

${ }^{10}$ Henry James Sims, estadunidense, formou-se na Escola de Educação Física da YMCA em Chicago e ocupou o cargo de diretor físico da ACM do Rio de Janeiro. Renato Eloy de Andrade estudou na instituição de Chicago e diplomou-se como diretor físico no Instituto Técnico das Associações Cristãs de Moços.

11 Mocidade, fevereiro de 1925, n. 372, p. 4.

12 Mocidade, dezembro de 1924, n. 370, p. 13 (grifos do autor).

${ }^{13}$ Revista Educação Physica, n. 1, 1º semestre, 1932.
} 
aluno, reveladas por um exame de sanidade feito no proprio Colégio" ${ }^{14}$. A vinda de docentes com formação e atuação nos Estados Unidos para conduzir o início dos trabalhos de tais estabelecimentos escolares era uma constante. Na disciplina específica de Educação Física, a presença lastreada da YMCA nos Estados Unidos, sua estrutura protestante e a afinidade com os valores que permeavam seu projeto formativo parecem habilitar a ACM como parceira para a distinção do professorado nos colégios protestantes.

Embora reconhecesse que sua obrigação principal era prestar serviços aos próprios sócios, o Departamento de Educação Física da ACM adotava o compartilhamento de seus serviços técnicos com organizações que tinham preocupações similares às suas. "Para a realização desta parte do seu programma, partilhará com ellas a sua direcção technica e preparará os socios para o serviço altruistico, dentro e fóra da ACM, pois o serviço altruistico é a pedra de toque do caracter christão" ${ }^{15}$. Assim, a Associação reafirmava a parceria constituída com alguns estabelecimentos de ensino como o já citado Colégio Batista do Rio, o Instituto Evangélico de Lavras, o também citado Colégio Granbery de Juiz de Fora, bem como, chamava a atenção para um valor caro à cultura estadunidense, que os brasileiros ainda precisariam incorporar. Anísio Teixeira (2006), em registro de suas impressões de viagem aos Estados Unidos ao final da década de 1920, descreve e dá visibilidade a um conjunto de "aspectos americanos de educação". Na narrativa do educador, a indicação do que ele chamou "de uma das mais profundas oposições entre a psicologia do nosso povo e a psicologia do americano". Referia-se Anísio à ideia de dedicação a um serviço, que nos Estados Unidos orientava a atividade educativa e era organizadora do país, em detrimento do "eu", da personalidade, que imperava entre os brasileiros. Lamentava o autor: "No Brasil, ajudar um ao outro é enfraquecer-se e favorecer o sucesso alheio". Afirmava ser quase impossível no país a cooperação, que na América era "uma espécie de senha nacional” (TEIXEIRA, 2006, p. 116). Anísio, ao dizer da educação dos jovens estadunidenses, produz uma narrativa bem afinada com o projeto de formação forjado na ACM:

O tipo moço de civilização deste país tem, não literariamente, mas concretamente, realmente, todas as qualidades de mocidade. Essas nobres qualidades de esquecimento de si mesmo e de uma constante e despreconcebida e quase involuntária dedicação a uma causa ou a um serviço (TEIXEIRA, 2006, p. 117).

O protestantismo, amparado, especialmente, pelos missionários americanos, buscava penetração nos recantos do país (MONIZ BANDEIRA, 2007). A adesão e conversão de brasileiros à fé reformada era uma conquista para o lastro das iniciativas acemistas no Brasil. $\mathrm{Na}$ busca de empreender um projeto de formação de moços brasileiros, a ACM, ao intentar atuar como salvadora de uma juventude marcada por condições adversas, foi também protagonista no movimento missionário que aqui se instalou.

Se a ressonância do protestantismo compôs um cenário de possibilidades, as condições de inserção da ACM no Brasil também foram constituídas pela produção de uma imagem positivada dos Estados Unidos em terras brasileiras, bem como de interpretações acerca do Brasil que circularam na instituição.

\section{PARA O CORPO, PARA OS COSTUMES, PARA AS SENSIBILIDADES: VESTÍGIOS DE PRÁTICAS CULTURAIS ESTADUNIDENSES}

Com a chegada de instituições e sujeitos estrangeiros, aportavam no Brasil modos de viver expressos em bens e produtos, em múltiplas linguagens, em comportamentos - sintonizados com padrões estadunidenses de operar no mundo. Códigos dos Estados Unidos expressos na educação, na

\footnotetext{
14 Revista Educação Physica, n. 1, $1^{\circ}$ semestre, 1932, s/p.

${ }_{15}$ Mocidade, fevereiro de 1925, n. 372, p. 7 (grifos do autor).

${ }^{16}$ O relatório de viagem de Anísio Teixeira aos Estados Unidos nos anos de 1920 e seu diário de viagem foram reunidos em um livro organizado por Clarice Nunes. 
ciência, na saúde, nos negócios, compunham um cenário amplo, no qual outros elementos da cultura estrangeira faziam-se presentes.

No texto publicado em O jornal no ano de 1919, intitulado Frog-trott, referências de uma positivada imagem dos estadunidenses:

Uma bella noite, alguns americanos, chegados, havia pouco, áquella cidade, invadiram o curso. Encantada, Margarida dobrou os preços e lhes fez o melhor acolhimento.

Dentro em pouco, porém, já cansados das polkas e valsas enfadonhas, os recemvindos entraram a confabular.

-“One step”! pediu de repente um delles, dirigindo-se á pianista.

Houve um movimento de pasmo.

- "One step", repetiu o rapaz com energia.

(...)

No dia seguinte, os americanos, voltando com um phonographo fanhoso, que tocava suas musicas preferidas, emprehenderam elles mesmos a instrucção dos alumnos. Dentro de oito dias, todo o mundo sabia dansar á americana... Começavam os namoros... Os yankees foram convidados pelas familias... Houve projectos de noivados... As mães exultaram.

(...)

Aquellas dansas eram de um humor encantador. Mme. Le Gagnat perseguida por um major de cabellos grisalhos, sentia desabrochar em si uma tardia primavera. Eva, transfigurada, trocava promessas de felicidade com um sócio da Associação Christã de Moços, de compleição robusta. A propria pianista punha um laçarote côr de rosa nos seus cachinhos louros e cobria de olhares languidos um rapagão, o qual ainda não se tinha apercebido disso ${ }^{17}$.

Bem afortunados, portadores de energia e de boa constituição física, a imagem produzida pela leitura do artigo sugere que aqueles que vinham dos Estados Unidos seriam capazes de combater a monotonia com espirituosidade, de renovar os sentimentos pessoais e de ensinar, com eficiência, elementos de sua cultura. O modo como é citada a Associação Cristã de Moços revela como o investimento no corpo é representada como uma referência da instituição.

Se o texto sugere uma aproximação cultural entre brasileiros e estadunidenses, os agentes missionários recorriam também a outras formas de linguagem como estratégia para a assimilação de sua identidade. Era o caso da bandeira dos Estados Unidos em evento do Colégio Batista, no qual participaram membros do Departamento de Educação Física da Associação Cristã de Moços carioca. Na imagem que mostra com destaque uma pirâmide humana, o símbolo cívico marca presença.

17 O jornal, 27 de agosto de 1919. p. 2. 
Figura 2: Membros do Departamento de Educação Physica da A.C.M. do Rio em uma festa do Collegio Baptista

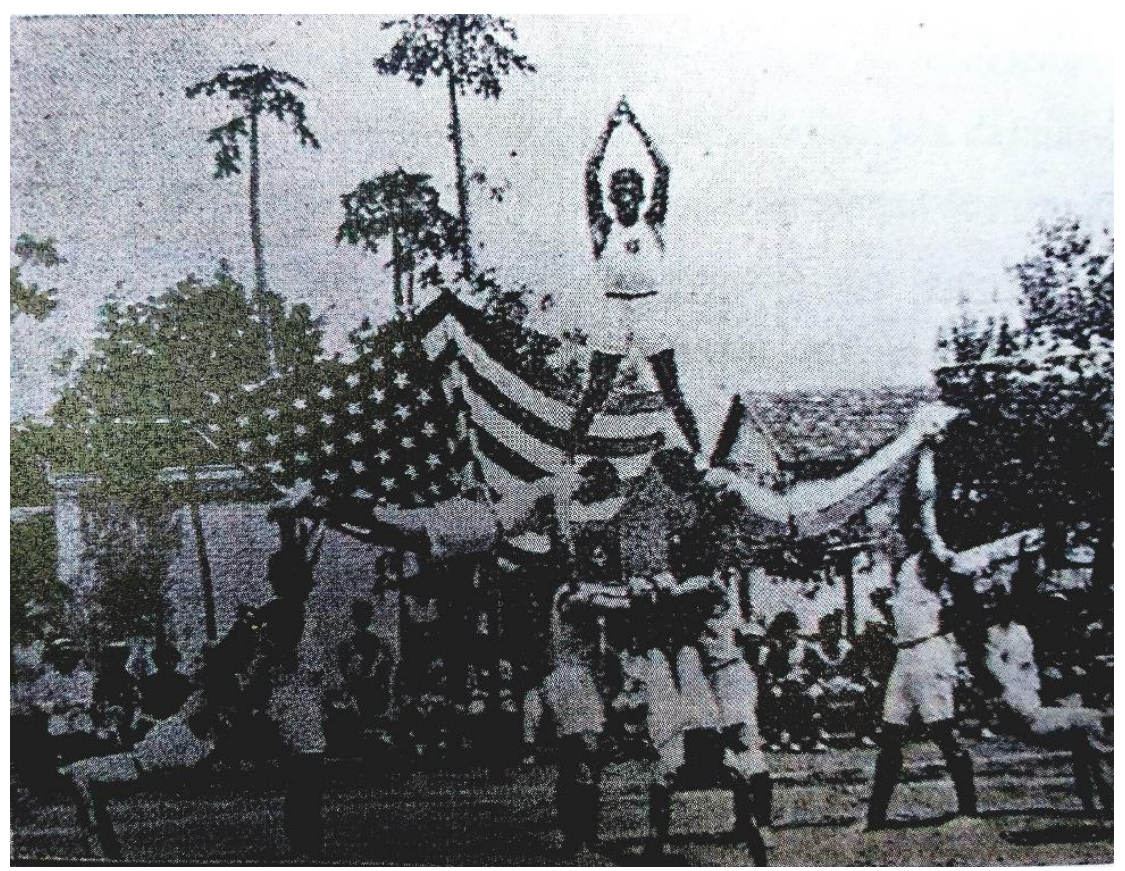

Fonte: Mocidade, março de 1922, n. 337, p. 5.

Ora de forma sutil, ora de modo explícito, é possível identificar um conjunto de elementos mobilizados também pela ACM para aproximação dos brasileiros com práticas culturais, com valores, com o modo de vida "americano". Em 1919, a Associação publicava em seu periódico a tradução de um texto intitulado Codigo de Costumes, premiado no estado de Ohio, que tematizava condutas morais para crianças $^{18}$. Constituída de dez leis, a narrativa remetia a costumes relacionados à saúde, ao governo de si, ao jogo, ao trabalho, ao dever, à confiança, à bondade e à lealdade, os quais o "bom americano" deveria praticar. Referências culturais potenciais para compor práticas acemistas no Brasil. A conservação da boa saúde para o trabalho diário; o governo do temperamento para não permitir a prática de desejos tolos; a ação honesta para ser merecedor da confiança alheia; o exercício do jogo desinteressado, sem trapaças, interesses ou em troca de dinheiro, e o trabalho em cooperação são destacados como costumes a serem incorporados pelo bom cidadão estadunidense. Essa maneira de moldar os sujeitos naquele país estrangeiro relacionou-se com elementos que compunham as "maneiras de fazer" educação física no projeto de formação da ACM.

Como produções sociais, datas festivas e modos de comemoração também tiveram sentidos acomodados no Brasil por mãos estadunidenses. O periódico O jornal anunciava: "feliz a iniciativa da Associação Christã de Moços, instituindo entre nós a comemoração belissima do 'Dias das Mães", celebração "já instituida por lei nos Estados Unidos, e que no Brasil vae a caminho, de identica consagração. A data já lhe está definitivamente fixada, no segundo domingo do maio de cada anno"19. Ao mesmo tempo em que traziam seus costumes e os faziam circular no Brasil, os acemistas deparavamse com outras referências culturais e manifestavam estranhamento e recusa. O carnaval era a expressão de muitos dos comportamentos condenados pela Associação - "luxúria", "prazeres da carne", "mulheres seminuas", "sedução", "contágio de insensatez". Diante dessa experiência festiva, a ACM produzia esforços para a não-adesão aos dias "de pecado". A responsabilização individual era a tônica - "Póde então um crente procurar assistir e ver, ou tomar parte em taes divertimentos? Não, peremptoriamente" acompanhada de um tom intimidador: "Não pratique, pois, o crente nesses dias, o que jamais seria capaz de praticar em outro qualquer dia do anno, por medo do ridiculo, ou receio da sociedade, mas, acima de

\footnotetext{
18 Mocidade, março de 1919, n. 301.

19 O jornal,10 de maio de 1920, p. 3.
} 
tudo, pelo temor de Deus!" ${ }^{20}$. Os argumentos acemistas pareciam centrar-se na manutenção do estado de graça dos sujeitos, conceito que, segundo a obra de Max Weber (2005) sobre a ética protestante, referese a "um estado que demarca seu portador fora da degradação da carne" e comum às diferentes manifestações do protestantismo (p. 115) ${ }^{21}$. O carnaval, reconhecido pela Associação como 'festa da carne', concorreria para a ruína moral dos moços. Símbolo dessa prática popular, a máscara é tomada pela ACM como um sustentáculo para a depravação, pois, sob sua proteção o homem poderia dizer e praticar "coisas" que não fariam com o rosto descoberto. Diante dos perigos oferecidos pelos festejos carnavalescos, os votos acemistas desejavam "que os moços christãos [dessem] um exemplo vivo de virtude e virilidade no meio da luxuria e animalidade destes dias de frenezi carnal”22.

\section{AS REPRESENTAÇÕES PRODUZIDAS SOBRE O BRASIL: COSTUMES E SENSIBILIDADES A EDUCAR}

O estado de graça dos brasileiros estaria em constante ameaça pelas condições do contexto do país, firmemente lembradas nos documentos da instituição. Os males que afetavam as condições morais do Brasil estavam descritos em um questionário relativo ao período de 1920 a 1924 e encaminhado ao Departamento Estrangeiro do Comitê Internacional da YMCA em Nova Iorque ${ }^{23}$. Foram encontrados dois documentos datilografados em língua inglesa: um relativo ao Rio de Janeiro, no qual constam apenas as respostas; outro, referente à cidade de Recife que apresenta também as questões ${ }^{24}$. Nos registros encontrados, as condições morais desses lugares eram descritas com ênfase em dois "grandes males": um relacionado ao sexo; outro, aos jogos de azar. No Rio, "entre as coisas que ajudam a prejudicar o caráter, certamente nada é pior do que os ideais baixos com referência à higiene sexual" ${ }^{25}$. $\mathrm{Na}$ capital pernambucana chamava a atenção o "(...) grande número de mulheres nas ruas principais, caminhando e em automóveis, depois das oito da noite. Provavelmente não se vê uma mulher na rua neste momento, que não é uma prostituta" ${ }^{\text {26 }}$. Orientada por seus referenciais religiosos, a ACM condenava a prática sexual desmoralizada.

Ainda como um mal a ser combatido, figuravam os jogos de azar. Em Recife, a justificativa para a adesão a tais práticas centrava-se na falta de espaços e atividades para melhor ocupar o tempo livre. "O jogo é realizado em todos os clubes, em casas e, em grande medida, devido à falta de nada melhor para fazer, com poucas instalações recreativas e com tempo em suas mãos, jovens e homens mais velhos caem em piores práticas" ${ }^{\prime 27}$. Para combater o malefício, a instalação de playgrounds e a promoção de jogos

20 A.C.M., 24 de fevereiro de 1900, p. 2 (grifo do autor).

${ }^{21}$ Para este artigo utilizo como referência a edição de "A ética protestante e o espírito do capitalismo" organizada por Sílvio Sant'Anna e publicada em 2005 pela editora Martin Claret, em sua coleção a obra-prima de cada autor.

22 A.C.M., 15 de fevereiro de 1901, p. 2.

${ }^{23} \mathrm{Em}$ sua quase totalidade, as fontes analisadas nesta seção foram acessadas presencialmente nos Kautz Family YMCA Archives, em Minneapolis, nos Estados Unidos. O arquivo faz parte da biblioteca da Universidade de Minnesota e como espaço de preservação da memória da Young Men's Christian Association apresenta potencialidades para pesquisas históricas interessadas em dar visibilidade aos sujeitos, às ideias e às experiências promovidas na e pela YMCA em espaços e tempos sociais diversos. Seu conjunto documental é formado por registros de arquivo que incluem atas de reuniões, correspondências e memorandos, pesquisas e relatórios, recortes de notícias, registros financeiros e de pessoal, panfletos, mapas, gráficos, esquemas; por fotografias, postais e álbuns de recortes; por vídeos e gravações de áudio; por pôsteres e panfletos que informam sobre eventos, programas e campanhas de divulgação da Associação; por objetos tridimensionais; por livros, reunidos em mais de 5.000 exemplares; e por periódicos. Disponível em <https://www.lib.umn.edu/ymca/collection-information>. Acesso em 19.02.2020.

${ }^{24}$ A sede da ACM em Recife foi criada em 1907. Baía (2012) indica sua extinção, ainda que seja imprecisa a data do encerramento de suas atividades. O autor afirma que "ao se analisar as edições da revista Mocidade, encontra-se, a partir de 1924, uma ausência de informações referentes à sede de Recife. No mesmo sentido, na VII Convenção das ACMs no Brasil, realizada em 1929, não há sinais da presença da Associação Cristã de Moços de Recife” (p. 21).

25 Survey 1920-24. Questionnaire for Rio de Janeiro, Brazil. p. 6. Box 2. YMCA International work in Brazil: an inventory of its records. Kautz Family YMCA Archives. University of Minnesota (tradução livre).

${ }^{26}$ Survey 1920-24. p. 6. Box 6. YMCA International work in Brazil: an inventory of its records. Kautz Family YMCA Archives. University of Minnesota (tradução livre). Escrito em letra cursiva, tem-se o registro no documento de Recife, Brazil.

27 Survey 1920-24. p. 6. Box 6. YMCA International work in Brazil: an inventory of its records. Kautz Family YMCA Archives. University of Minnesota (tradução livre). Escrito em letra cursiva, tem-se o registro no documento de Recife, Brazil. Educação em Revista|Belo Horizonte|v.36|e222213|2020 
atléticos, era o que sugeria o relator do contexto recifense. Os destaques no Rio recaiam sobre a permissividade do Estado e da Igreja em relação aos jogos e sobre uma produção nacional: o jogo do bicho.

A loteria oferece ao homem todos os dias a chance de ganhar uma grande soma sem economizar e todo homem espera que seu dia de sorte venha; portanto, os brasileiros, como um todo, não economizam.

Há um esforço para evitar jogos de azar para o homem pobre conhecido como o "bichu" ou o jogo animal. É, obviamente, mal sucedido e será sempre que a loteria funcione com a sanção federal e da igreja.

Há boas leis contra os jogos de azar, mas aqui também ninguém realmente espera ver as leis cumpridas enquanto a loteria continuar a existir ${ }^{28}$.

Os questionários produzidos apresentam-se como representações sobre o Brasil que circularam entre os acemistas estrangeiros, ao mesmo tempo que oferecem indícios para compreender motivações e interesses que justificaram o empreendimento da Associação no país. Constituída como importante lugar social que produziu referências e prescrições sobre temáticas educacionais, a YMCA estudava as condições brasileiras que possibilitassem a ressonância de seu projeto formativo em andamento, posto que as referidas sedes já tinham sido inauguradas. O questionário mencionado expressa um diagnóstico sobre as cidades, uma vez que as questões versavam sobre diferentes temáticas que envolviam a realidade brasileira: dados populacionais, subsídios para compreender o nível de alfabetização e educação, informes sobre condições de saúde e qualidades morais, elementos sobre a ocupação do tempo livre, informações comerciais e econômicas, dentre outros dados relativos à estrutura da Associação naquelas cidades.

A percepção do contexto brasileiro indicava uma população em sua metade analfabeta, nas duas cidades pesquisadas. A curiosidade acemista sobre aqueles que poderiam também ler e escrever em inglês foi sanada por números mínimos. Dados que possivelmente orientaram ações no interior das sedes; exemplo disso pode ser a tradução de textos da língua inglesa para a portuguesa publicados no periódico oficial da Associação. O acesso a uma produção estrangeira não se daria em língua original, demandava uma mediação.

Impressões similares são descritas para as condições de saúde em Recife e no Rio. Destaques para o combate à febre amarela e para as precárias condições de habitação do povo. Para a cidade carioca, chamou-se a atenção para um tipo específico de moradia: "Frequentemente, um grande número de jovens está associado ao que é conhecido como 'República' onde as refeições geralmente são fornecidas. Esses lugares são comumente conhecidos como centros de influência imoral" 29 .

A possibilidade de degradação moral também se encontrava nos momentos de tempo livre. Em Recife, "de recreação, há muito pouco. A vida está vazia, com muito (sic) poucos meios de diversão. A maior parte do tempo dos jovens é gasto nas ruas, na conversa. Naturalmente, essa é uma das razões pelas quais o número de prostitutas é tão grande"30. Contudo, chamava-se atenção para o cinema, ali bem administrado e digno. No Rio, a presença de jovens nas ruas e a relação ali estabelecida com as mulheres foi descrita de forma mais suave. Além de assistir a filmes e frequentar teatros, os homens ficavam parados ou caminhando lentamente na avenida e teciam "observações" sobre as damas que passavam. A prática de futebol, remo, natação e tênis foi também narrada, bem como a elevação moral promovida pelos jogos atléticos. No contexto da recreação, um dado que poderia ser incômodo para os acemistas, especialmente, aqueles protestantes mais rígidos, o emprego do domingo para práticas esportivas. "O dia mais popular para praticamente todos os esportes é domingo quando muitos jovens, porque não podem realizar exercícios em nenhum outro momento, se dedicam ao excesso e estão menos preparados para o

\footnotetext{
${ }^{28}$ Survey 1920-24. Questionnaire for Rio de Janeiro, Brazil. p. 6-7. Box 2. YMCA International work in Brazil: an inventory of its records. Kautz Family YMCA Archives. University of Minnesota (tradução livre) (grifos do autor).

${ }^{29}$ Survey 1920-24. Questionnaire for Rio de Janeiro, Brazil. p. 3. Box 2. YMCA International work in Brazil: an inventory of its records. Kautz Family YMCA Archives. University of Minnesota (tradução livre) (grifos do autor).

${ }^{30}$ Survey 1920-24. p. 4. Box 6. YMCA International work in Brazil: an inventory of its records. Kautz Family YMCA Archives. University of Minnesota (tradução livre).
} 
trabalho no dia seguinte" ${ }^{\prime 1}$. Na resposta ao questionário, o entrave ressaltado para a realização de jogos no domingo estava ligado à dimensão do trabalho, mas, poderiam existir ainda outras razões religiosas que contestassem o uso de tal dia. Duas décadas antes do referido questionário, a ACM publicava um entendimento sobre o repouso no domingo: "Renunciemos alegremente nós mesmos o trabalho do domingo e os prazeres mundanos para o bem de nossa alma, para o bem de nossos semelhantes e para obedecer a nosso divino Mestre, ainda que custe algum sacrificio". Nas palavras sugestivas, atividades desejáveis para o dia: "Consagremos o dia do Senhor a repousar de nossos trabalhos da semana e a nos occupar das obras christãs: culto publico, escolas dominicaes, evangelisação da mocidade; visitas aos doentes, aos velhos, etc., etc." ${ }^{\prime 2}$. Vale ressaltar que ao longo dos anos os modos de viver o dia de domingo colocaram-se como questão polêmica no interior da Associação. O entendimento antes consagrado foi redimensionado a partir de uma negociação para atender demandas da própria ACM.

À Associação interessava ainda saber sobre as facilidades para a abertura de playgrounds na cidade. As respostas eram bem animadoras. Em Recife, "o trabalho com playground poderia muito bem ser incitado e receberia a sanção do governo" 33. No Rio, diálogos para empreender a ação pareciam já iniciados: "Nós falamos com vários líderes da vida brasileira com referência ao desenvolvimento de playgrounds e estamos convencidos de que devemos encontrar assistência pública e governamental pronta quando pudermos fornecer líderes para direcionar o trabalho" ${ }^{34}$. Um país de possibilidades, assim também o Brasil aparecia relatado.

Vestígios que perspectivavam o país em condições de ter o projeto acemista lastreado foram também encontrados no documento Brasil, review of the situation in the country. O relato sobre o país não tem indicação de autoria e apresenta-se datilografado em língua inglesa. $\mathrm{Na}$ narrativa, são tratadas diferentes temáticas, como as condições sociais e políticas brasileiras, entretanto, o documento é dedicado em sua maior parte às discussões sobre a economia no país, aproximadamente duas folhas, e sobre questões religiosas, que ocupam em torno de quatro folhas e versam sobre convicções brasileiras, condições favoráveis ao evangelismo, estatísticas de desenvolvimento de igrejas evangélicas e o lugar da Associação na expansão do espírito cristão.

Economicamente, o Brasil era destacado como um país de vários recursos ainda inexplorados e de uma ilimitada capacidade útil para a humanidade. O que lhe faltava eram investimento e formação pessoal. Afirmava o relator que "inquestionavelmente, o país precisa de capital e gênio para a organização, mas muito mais que isso, é a necessidade de disponibilizar seus possíveis recursos na masculinidade

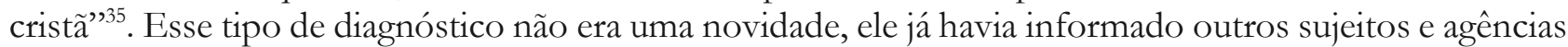
estadunidenses no sentido de produzir empreendimentos também de ordem econômica no Brasil. Tota (2000) afirma que durante muito tempo, "o americanismo havia forjado uma imagem desabonadora da América Latina. Valorizava-se o homem branco, protestante, sempre mencionado como condutor do progresso na luta contra a vida selvagem e criava-se uma imagem oposta para os latino americanos" (p. 30). Diante da constatação da necessidade brasileira de capital e de genialidade para conduzir questões econômicas, recursos financeiros e competências de liderança e organização poderiam então ser partilhados pelos Estados Unidos. Para Tota (2000), os dispositivos de ação que colocavam o país estrangeiro como modelo, como "os projetos de saneamento e saúde e os programas econômicos tinham um sentido paradigmático, isto é, os Estados Unidos possuíam o segredo do progresso e, o que era mais importante, estavam 'dispostos' a compartilhá-lo com o Brasil” (p. 180, grifos do autor). Para compreender o Brasil como espaço de investimento da ACM, considero necessário ressaltar que o

\footnotetext{
${ }^{31}$ Survey 1920-24. Questionnaire for Rio de Janeiro, Brazil. p. 4. Box 2. YMCA International work in Brazil: an inventory of its records. Kautz Family YMCA Archives. University of Minnesota (tradução livre).

32 A.C.M., 1 de outubro de 1901, p. 3.

33 Survey 1920-24. p. 4. Box 6. YMCA International work in Brazil: an inventory of its records. Kautz Family YMCA Archives. University of Minnesota (tradução livre).

34 Survey 1920-24. Questionnaire for Rio de Janeiro, Brazil. p. 5. Box 2. YMCA International work in Brazil: an inventory of its records. Kautz Family YMCA Archives. University of Minnesota (tradução livre).

35 Brasil, review of the situation in the country, p. 1. Box 6. YMCA International work in Brazil: an inventory of its records. Kautz Family YMCA Archives. University of Minnesota (tradução livre). 
diagnóstico brasileiro era orientado por um mecanismo que ora indicava as condições desfavoráveis do país, ora as tomava como mote para a ressonância das iniciativas da Associação.

Para justificar os empreendimentos do projeto formativo da ACM, a construção da imagem de um povo que necessitava de intervenções de orientação religiosa. Socialmente, as relações estabelecidas entre o povo brasileiro estavam descritas como "a antítese exata do cristianismo. Isto é especialmente verdadeiro na concepção popular da função sexual" ${ }^{36}$. Diante desse contexto, o documento produzia uma profunda necessidade de que os princípios de Cristo fossem incorporados pelos jovens, especialmente no período formativo de seu desenvolvimento. Contudo, esse imperativo esbarraria no contexto religioso do país, a ausência de convicção cristã era apontada como um obstáculo a ser removido. "O povo em geral tem algum sentimento religioso, mas não há a convicção necessária sobre o que é o pecado, ou sobre o que é respeitar a lei de Deus ou a realização de sua presença em todos os lugares, etc.". Tal entrave era reforçado por um aspecto educacional atestado no país: o analfabetismo. "Não há dúvida de que o maior de todos os obstáculos no sentido de trazer convicção aos corações das pessoas que ouvem o Evangelho, é a prevalência do analfabetismo, infelizmente, em todo o Brasil" ${ }^{37}$. O trabalho de evangelização tinha na leitura da bíblia a condição básica para a conversão dos sujeitos, por isso também, a preocupação incessante com a instrução do povo (CHAMON, 2005).

Indicar limitações, mas também apresentar alternativas, essa parecia a dinâmica dos relatos diagnósticos encontrados nos arquivos YMCA. Operando com essa artimanha, a narrativa referenciava as possibilidades de parceria entre Brasil e Estados Unidos e evidenciava um esforço de forjar uma imagem de sintonia entre os dois países. Contudo, a reciprocidade não parecia o tom, mas sim a adequação dos brasileiros a referências estrangeiras.

Embora sua ideia de educação [a do brasileiro] seja uma forma bastante diferente da que prevalece na América do Norte, não há nada em sua prática ou atitude que torne impossível ou indesejável a cooperação com norte-americanos ou outros. Pelo contrário, ele [o brasileiro] é muito simpatizante em relação às ideias norte-americanas e mesmo aos ideais e muito pronto para adotar métodos norte-americanos ${ }^{38}$

A tônica pretendida consistia em reconhecer os Estados Unidos como um lugar emissor de padrões culturais, e o Brasil como país receptor. Mesmo que a dinâmica social interpusesse uma apropriação condicionada aos choques, às negociações, às rejeições, a produção acemista sobre o povo brasileiro parecia realçar a expectativa de uma simples adequação cultural. Em documento que declarava a necessidade de um edifício para sede da ACM em São Paulo, sem anotação de data, o recurso às precárias condições brasileiras e à autoridade externa como resolução dos problemas é mobilizado a partir da citação de um pastor protestante, Eduardo Pereira.

\footnotetext{
"A incerteza moral da sociedade brasileira e o abatimento dos espíritos liberais de nosso país, que esperam por um libertador, dão às missões protestantes uma oportunidade única que logo passará. O espírito nacional está aberto a qualquer esperança que nos pode ser oferecida no caos moral e religioso. Parece, além disso, que as forças missionárias, no Brasil, são urgentemente chamadas a ajudar em um novo espírito, com novos métodos, novos planos, novos recursos. A Associação Cristã de Moços, bem compreendida e dirigida, deve ser um excelente meio em si de colocar o Evangelista em contato com o jovem" 39 .
}

\footnotetext{
${ }^{36}$ Brasil, review of the situation in the country, p. 2. Box 6. YMCA International work in Brazil: an inventory of its records. Kautz Family YMCA Archives. University of Minnesota (tradução livre).

${ }^{37}$ Brasil, review of the situation in the country, p. 4. Box 6. YMCA International work in Brazil: an inventory of its records. Kautz Family YMCA Archives. University of Minnesota (tradução livre).

${ }^{38}$ Brasil, review of the situation in the country, p. 3. Box 6. YMCA International work in Brazil: an inventory of its records. Kautz Family YMCA Archives. University of Minnesota (tradução livre).

${ }^{39}$ São Paulo, Brazil: statement of need of a central building, p. 3. Box 5. YMCA International work in Brazil: an inventory of its records. Kautz Family YMCA Archives. University of Minnesota (tradução livre). Educação em Revista|Belo Horizonte|v.36|e222213|2020
} 
Referenciado na afirmação de que "pensadores" brasileiros estavam à procura de influências que pudessem contribuir para a construção do caráter dos jovens e educá-los para uma cidadania útil, o documento apresentava uma interpretação sobre o Brasil que agregava interesses acemistas.

Embora não tenha sido possível seguir os rastros dos personagens que produziram esses diferentes documentos diagnósticos - alguns, inclusive, sem referência autoral -, destaque-se a possibilidade de seus emissores atuarem nesse lugar jogando com as circunstâncias que estavam envolvidos. Apesar de alguns relatos também não serem datados precisamente, essas narrativas apresentam dados que supõem que a ACM já estava estabelecida no Brasil, inclusive com as sedes instaladas no Rio de Janeiro, em Recife e em São Paulo. Uma vez já iniciado o empreendimento acemista, não seria necessário reforçar o Brasil como lugar de possibilidades para seu projeto formativo? Os elementos trazidos para a cena não precisariam colocar cada qual no seu lugar: o Brasil como agente passivo e as referências estadunidenses como orientadoras do progresso, dos bons costumes, da boa educação? A busca da YMCA por um diagnóstico do Brasil produziu uma trama em que versões sobre o país foram reconstruídas, ideias foram remodeladas, vozes foram silenciadas. Tal interpretação pode ser analisada com alguma desconfiança.

Ressalte-se que as iniciativas da ACM merecem ser analisadas como mais um signo de um projeto cultural maior. A penetração do protestantismo no país é um dos múltiplos elementos estadunidenses que se espraiava por alguns centros brasileiros. Warde (2000) aponta que:

\footnotetext{
A partir de meados do século XIX, os Estados Unidos representam um espelho no qual o Brasil deveria se mirar. Sem suspender as especulações em torno do que o Velho Mundo poderia oferecer ao nosso futuro, a cultura norte-americana se apresenta como o melhor dos horizontes possíveis, porque além de ser a expressão de uma sociedade que constrói a sua própria identidade, oferece a todos as chances de uma vida de progresso e democracia (p. 37).
}

Diante das fragilidades do contexto brasileiro, a narrativa dos diagnósticos reflete a aposta na ideia de que a mirada em agentes externos produziria uma espécie de salvação para os problemas nacionais. A genialidade, o capital, os bons costumes, a convicção religiosa, precisariam ser importados, visto que aqui, apesar dos pesares, havia a possibilidade de novas adequações. A YMCA, imbuída da ideia do destino manifesto, colocava-se em um lugar autorizado para oferecer aos brasileiros chances de uma vida para o progresso. Eram novos modos de agir, de sentir, de constituir-se fundamentalmente por uma educação que passava pelo corpo. As iniciativas proferidas como alternativas para as carências brasileiras - faltava convicção religiosa, conduta moral, capital, genialidade, dentre outras - compuseram uma trama forjada com uma certa artimanha, para que, como autoridades e intérpretes da ambiência brasileira, os acemistas empreendessem seu projeto formativo.

\section{REFERÊNCIAS}

BAÍA. Anderson da Cunha. Associação Cristã de Moços no Brasil: um projeto de formação moral, intelectual e física (1890-1929). 2012. 214 f. Tese (Doutorado em Educação) - Faculdade de Educação da UFMG, Belo Horizonte, 2012.

CALVANI, Carlos Eduardo B. A educação no projeto missionário do protestantismo no Brasil. Revista Pistis \& Praxis Teologia e Pastoral. Curitiba, v. 1, n. 1, p. 53-69, jan./jun. 2009.

CHAMON, Carla Simone. Maria Guilhermina Loureiro de Andrade: a trajetória profissional de uma educadora (1869/1913). 2005. 338f. Tese (Doutorado) - Faculdade de Educação da Universidade Federal de Minas Gerais, Belo Horizonte, 2005. 
MENDONÇA, Antonio Gouvêa. O celeste porvir: a inserção do protestantismo no Brasil. São Paulo: Paulinas, 1984.

MESQUIDA, Peri. Hegemonia norte-americana e educação protestante no Brasil. Juiz de Fora: EDUFJF; São Bernardo do Campo: Editeo, 1994.

MEURER, Sidmar dos Santos; TABORDA DE OLIVEIRA, Marcus Aurelio. A invenção dos recreios nas escolas primárias paranaenses: o lugar da educação do corpo, dos sentidos e das sensibilidades na escola. Revista Brasileira de Educação, Rio de Janeiro, v. 21, n. 64, p. 225-247, jan./mar. 2016.

MONIZ BANDEIRA, Luiz Alberto. Presença dos Estados Unidos no Brasil. Rio de Janeiro: Civilização Brasileira, 4 ed., 2007.

OLIVEIRA, Lúcia Lippi. A ilusão americana. In: MOTA, Lourenço Dantas (Org.). Um banquete no trópico, 1. 4 ed. São Paulo: Editora Senac, 2004. p. 133-150.

RAMALHO, Jether P. Prática educativa e sociedade: um estudo de sociologia da educação. Rio de Janeiro: Zahar, 1976.

SEVCENKO, Nicolau. A metrópole irradiante: técnica, ritmos e ritos do Rio. In: SEVCENKO, Nicolau (Org.). História da vida privada no Brasil. São Paulo: Companhia das Letras, 1998. v. 3. p. 513-619.

SILVA, Giovanna Camila da. A Associação Cristã de Moços e experiências de escolarização da Educação Física no Brasil: sujeitos, ideias e práticas acemistas em circulação. 2017. 236 f. Tese (Doutorado em Educação) - Faculdade de Educação da UFMG, Belo Horizonte, 2017.

TEIXEIRA, Anísio. Aspectos americanos de educação \& Anotações de viagem aos Estados Unidos em 1927. Organização: NUNES, Clarice. Rio de Janeiro: Editora UFRJ, 2006. (Coleção Anísio Teixeira, v. 1).

TOTA, Antonio Pedro. O imperialismo sedutor: a americanização do Brasil na época da Segunda Guerra. São Paulo: Companhia das Letras, 2000.

WARDE, Mirian Jorge. Americanismo e educação: um ensaio no espelho. São Paulo em Perspectiva, São Paulo, v. 14, n. 2, p. 37-43, 2000.

WEBER, Max. A ética protestante e o espírito do capitalismo. Traduzido por: Pietro Nassetti. Organização: SANT’ANNA, Sílvio. São Paulo: Martin Claret, 2005. (Coleção a obra-prima de cada autor). 